Ger J Exerc Sport Res 2021 · 51:390-393 https://doi.org/10.1007/s12662-021-00726-6 Received: 16 April 2021

Accepted: 13 May 2021

Published online: 28 June 2021

๑) Springer-Verlag GmbH Deutschland, ein Teil von Springer Nature 2021

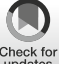

Mariella Scerri' ${ }^{1}$ - Victor Grech ${ }^{2}$

' University of Leicester, Leicester, UK

${ }^{2}$ Mater Dei Hospital, Msida, Malta

\title{
Discussion: COVID-19's impact on sports and athletes
}

negative consequences for all athletes in relation to the cancellation and postponement of such events during these fraught times need to be taken seriously. The current COVID-19 crisis requires a rigorous system that ensures greater accountability on the part of event organisers, while ensuring that the athletes' voice is heard (Mann, Clift, Boykoff, \& Bekker, 2020).

This commentary begins with a description of how athletes were affected during the current COVID-19 pandemic. It will also discuss the role of the athletes during a pandemic. In this age of social media, athletes have a key role to play. News of inappropriate behaviour can spread very quickly, particularly when the behaviour evokes an emotive response. However, social media can also be leveraged to spread positive messages. During this pandemic, athletes like other celebrities can act as role models. They can encourage appropriate behaviours including social distancing to help stall the spread of the virus through social media. Hence a short discussion on the future of athletes as role models during a pandemic is merited. The paper ends with a short discussion on the resumption of sports after lockdown. In such a context of uncertainty, maximum caution is needed for resumption of sports to ensure a smooth return to previous high levels of training and fitness.

\section{Dysfunctional impact on athletes' performance during COVID-19}

During these turbulent times, high levels of stress have a negative effect on our sense of well-being (Weinberg \& Cooper,
2012). The mitigation measures of social distancing further exacerbate the negative effects of stress. It is well documented that an overall lack of social interaction with others hinders general wellbeing (Segrin \& Rynes, 2009). Given the detrimental effects on the individual's emotional and bodily experience (Weinberg \& Cooper, 2012), the impact of this worrisome and stressful situation could also extend to "athletes' emotional experiences and emotion-related psychobiosocial states, exerting a functional or dysfunctional impact on performance" (Chen et al., 2020a). Absence of organized training and competition, lack of adequate communication between athletes and coaches, inability to move freely, and inappropriate training conditions are negative consequences of social isolation or quarantine (Chen et al., 2020a). Staying in quarantine can have deleterious effects, not only on most physiological systems, but also in the players' lives. Although it is difficult to predict the duration of the global COVID-19 crisis at this time, it is possible to anticipate the loss incurred with training-induced adaptation. In this scenario, it is therefore extremely important to identify the effects and to understand the mechanisms and effects on all physiological systems, as well as their impact on athletic performance.

Reductions in maximal and submaximal exercise performance occur within weeks after the cessation of training and the losses in aerobic performance have shown that they decrease cardiovascular function and muscle metabolic potential. Reduced or complete absence of strength training can also cause loss of muscle mass while periods of prolonged inactivity negatively affect the anti-gravitational 
muscle groups and the posterior extensor muscle chain (Boonyarom \& Inui, 2006). Unfortunately, there is limited literature which allows a direct translation of such observations to the current situation, as available evidence has focused on postinjury conditions (Chen et al., 2020b) or on the detrimental effects of the off-season (Boonyarom \& Inui, 2006). Previous work can scarcely mimic the situation that athletes are experiencing now, with a sudden and longer than normal reduction in total training hours and the challenge to provide sport-specific stimuli. Nevertheless, disuse-based studies which hypothesize that, in a period of activity reduction, muscles and tendons will undergo alterations of a similar nature provide accurate results. Accordingly, since factors such as muscle strength and architecture have been suggested to influence injury risk, athletes may be more susceptible to injury during COVID-19 home confinement release (Kalkhoven, Watsford, \& Impelizzer, 2020).

Psychologically, athletes also have much to lose. Without constructive guidance and support, athletes who find themselves unforeseeably inactive or without direction, tend to suffer from substantive psychological stress and potential mental ill-health. Literature shows that lacking a career direction after years of immersing oneself in an intrinsic high-performance goal places athletes in peril (Schinke et al., 2020). Some of these athletes also suffer burnout. Personal feelings of alienation and poor coping responses, in this case, compounded by social isolation, have resulted for some in compromised mental health. Never has there been a more important moment for mental performance consultants to be accessible to their clients, and to validate the multitude of mixed thoughts and emotions experienced by aspirants. Access is needed to transcend availability, to the type of encouragement that could best serve each high-performance athlete (Schinke et al., 2020).

\section{The athletes' role during the pandemic}

In March 2020, National Basketball Association (NBA) player Rudy Gobert mocked prevention measures rules set up by NBA during the COVID-19 pandemic by touching every microphone and recorder intentionally during a media event. Off camera, Gobert also adopted a cavalier attitude towards the possibility of spreading the virus by exchanging high fives with his teammates and touching their personal belongings (Raskin, 2020). When Gobert tested positive for the COVID-19 virus days later, it led to the league-wide suspension of the NBA games for the remainder of 2019/2020 season (Aschburner, 2020). His teammate, Donovan Mitchell, was also subsequently infected with the virus. Gobert's actions were met with fierce criticism. As a professional athlete, Gobert was expected to be more responsible and act as a role model during this period. In trivialising the pandemic, his behaviour seemed to encourage both fans and the general public to disregard mitigation measures to prevent an escalation of the outbreak.

This incident raises the question of whether the public should hold professional athletes to a higher standard and expect them to be role models. Athletes are perceived to possess positive character traits including perseverance and discipline (Teigen, Normann, Björkheim, \& Helland, 2020). Through constant appearances in the media, they have also become familiar public figures (Lines, 2002). As a result, many young adults regard athletes as potential role models (Teigen et al., 2020). Athletes are thus expected by the public to behave appropriately both on-court and off-court so that they can be role models for the young.

While there is still debate as to whether professional athletes should be role models, the COVID-19 pandemic creates a situation where athletes should set good examples for their fans and encourage appropriate behaviours. This is especially so in this age of social media where information on the virus can spread faster than the virus itself (Depoux et al., 2020). Today, many people are members of social network sites. As members of a social network site have a relationship with each other in a virtual community, they are more likely to trust information posted and thus share them with other members (Phua \& Ahn, 2016). The nature of social network sites favours a quick emotive response rather than a prolonged, conscious and cognitive response (Leng, 2019). Social media can also transmit positive messages and encourage appropriate behaviours during a pandemic (Kim, 2020). Through social influence, celebrities can influence behaviour through normative influence. This is because there is a desire by others to emulate them (Deutsch \& Gerard, 1955). Hence, celebrities can share appropriate behaviours and encourage the public to act responsibly through social media.

Many athletes are already using social media to interact with their fans. These include sharing their training regimes, their activities with their families and friends, and their charity work (Smith \& Sanderson, 2015). As such, it is easy for athletes to leverage on this medium and encourage appropriate behaviours from both their fans and the public during this pandemic. As athletes are perceived to be fit and healthy, messages that they post on health-related matters will be deemed more credible and convincing than the average celebrity (Behnoosh, Naylor, \& Dickson, 2017). Athletes can thus make a difference in this fight against COVID19.

\section{Resuming sports after lockdown}

The COVID-19 pandemic has had, and will have, profound effects on every one. Measures advocated by the World Health Organisation (WHO), and put in place by national governments, businesses and individuals saved millions of lives; however movement restrictions might have negative effects on professional athletes. Professional sport and its resumption, is a secondary concern in the context of the COVID-19 pandemic globally; however, it still carries significant importance. Substantial planning and work are required for sporting events to resume (Carmody, Murray, Borodino, Gouttebarge, \& Massey, 2020). Athletes form part of a larger, more complex system-communities that include other athletes, their multidisciplinary support teams, families, and local, national and 
international societies. Recognising, holding space for and negotiating athletes as a community - as human beings who are part of this world rather than simply being commodities-has never been more important (Mann et al., 2020). By its very nature, elite sport is not equitable. Every athlete has a career trajectory that requires navigating several barriers and obstacles. However, in the aftermath of a communicable pandemic, these inequalities will become more apparent and dependent on different public health responses. Elite athletes will organise their training programmes toward major sport events; therefore this requires access to specialist facilities and multidisciplinary support teams. Furthermore, different approaches tailor made for different athletes need to be taken into consideration. Simply moving the timeline may not be enough. Indeed, a recent editorial advocated that "maximal caution" should be taken in resuming sport activities (Corsini, Bisciotti, \& Eirale, 2020). These considerations matter, and returning to sport will thus be about more than the resumption of training schedules and a revamped sports calendar.

This proved to be a particular challenge to the Italian Serie A footballers. A number of clubs pushed for training activities to resume for footballers to maintain their fitness level. However, this was met with strong opposition from Serie A doctors. Even though football players might have a low risk of death as a consequence of an infection by COVID-19 because of their young age, they could nevertheless develop severe respiratory failure requiring hospital admission (Corsini et al., 2020). Furthermore, football is a contact sport and football players are often in close contact with their teammates during their daily activities and camps. These factors put the players in a high risk of disease transmission. For these reasons, the profession of football does not allow compliance with the normal protection rules recommended by the WHO. Moreover, COVID-19 infection can cause chronic health consequences. Long-term complications to organs such as the heart (Zheng, Ma, \& Zhang, 2020), the lungs
(Chen et al., 2020b), the liver, kidneys, blood and the immune system are being documented (Wang, Du, \& Zhu, 2020). Therefore, in such a context of uncertainty, maximum caution is needed for resumption of sports. Specific protocols to check cardiac, pulmonary and, in general, systemic sequelae of COVID-19 before resuming sporting activities should be considered.

\section{Conclusion}

Major sport events can provide hope and unity. Amid an extraordinary public health challenge, optimism and solidarity matter more than ever. One cannot envisage what a return to sport will look like after this pandemic; however, we do already know that the community matters more than ever. Athletes are demonstrating that "social distancing is a misnomer": in their insistence to physically distance while encouraging others to do so, they show remarkable social interconnection. There has never been a time when athletes and those who worked with them needed to be more flexible and creative (Mann et al., 2020). The current pandemic offers opportunities that athletes and their providers must find. Lessons gained through autonomy, ingenuity, resilience, life balance, mindfulness, and many more possible skillsets, can and will mould strengthened and more resilient athletes. Moments of quietness present openings to reflect, re-evaluate, revise, and reform plans. These plans will undoubtedly be roads less travelled, but highly valued. The pervasiveness of these life lessons can serve athletes extremely well, as lives are never linear and paths are often circuitous (Schinke et al., 2020). Retrospectively, we can all agree that even when one believes one is standing still due to uncertainties, one never is. The human condition is such that people learn from their circumstances, and they adapt. The days ahead will provide fascinating data, dialogues, and interventions, built as a result of what could easily be dismissed as an isolated and unfortunate moment in human, and also, sport history. However, one cannot underestimate the strength of the human spirit (Schinke et al., 2020). Taking this
Ger J Exerc Sport Res 2021 · 51:390-393 https://doi.org/10.1007/s12662-021-00726-6 (c) Springer-Verlag GmbH Deutschland, ein Teil von Springer Nature 2021

\section{Scerri · V. Grech Discussion: COVID-19's impact
on sports and athletes}

\section{Abstract}

As major sport events have been cancelled and postponed in response to coronavirus disease 2019 (COVID-19), the necessity to protect and provide a holistic approach to the professional athlete has never been greater. To do so one must understand the negative consequences for athletes in relation to the cancellation and postponement of such events caused by a communicable pandemic. The aim of this paper is to give a brief overview of how athletes were affected during the current COVID-19 pandemic. It will also discuss the role of athletes during a pandemic. Athletes like other celebrities can be role models. They can encourage appropriate behaviours including social distancing to help stall the spread of the virus through social media. The article ends with a short discussion on the resumption of sports after lockdown. In such a context of uncertainty, maximum caution is needed for resumption of sports to ensure a smooth return to previous high levels of training and fitness.

Keywords

COVID-19 pandemic · Impact · Professional sports $\cdot$ Role models

physically isolating moment to reflect on athletes as whole human beings, situated in communities that they care about, enables us to adopt more of an athletecentred approach and provide health protection when they resume training in the future. The fierce urgency of this task has never been clearer.

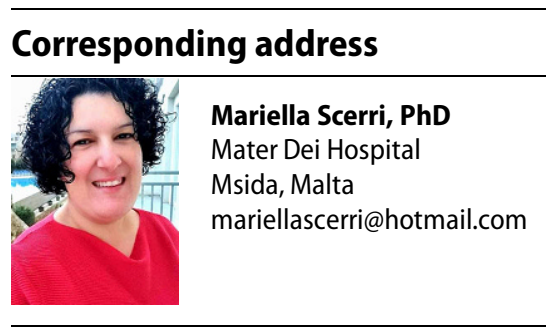

Mariella Scerri Medical Humanities candidate

Victor Grech Consultant Paediatrician (Cardiology) 


\section{Declarations}

Conflict of interest. M. Scerri and V. Grech declare that they have no competing interests.

No human subjects were involved so no ethical approval or data protection was applied for.

\section{References}

Aschburner, S. (2020). Coronavirus pandemic causes NBA to suspend season after player tests positive. https://www.nba.com/article/ 2020/03/11/coronavirus-pandemic-causesnba-suspend-season. Accessed 12 September 2020.

Behnoosh, S., Naylor, M., \& Dickson, G. (2017). Promoting sport and physical activity participation: the impact of endorser expertise and recognisability. Managing Sport and Leisure, 22(3), 214-233. https://doi.org/10.1080/23750472. 2018.1424024

Boonyarom, O., \& Inui, K. (2006). Atrophy and hypertrophy of skeletal muscles: structural and functional aspects. Scandinavian Physiological Society, 188,77-89.

Carmody, S., Murray, A., Borodina, M., Gouttebarge, V., \& Massey, A. (2020). When can professional sport recommence safely during the COVID19 pandemic? Risk assessment and factors to consider. British Journal of Sports Medicine, 54(16), 946-948. https://doi.org/10.1136/ bjsports-2020-102539.

Chen, P., Mao, L., Nassis, G. P., Harmer, P., Ainsworth, B. E., \& Li, F. (2020a). Coronavirus disease (COVID-19): the need to maintain regular physical activity while taking precautions. Journal of Sport Health Science, 9, 103-104.

Chen, N., Zhou, M., Dong, X., et al. (2020b). Epidemiological and clinical characteristics of 99 cases of 2019 novel coronavirus pneumonia in Wuhan, China: a descriptive study. The Lancet, 395, 507-513. https://doi.org/10.1016/S01406736(20)30211-7.

Corsini, A., Bisciotti, G. N., Eirale, C., et al. (2020). Football cannot restart soon during the COVID19 emergency! A critical perspective from the Italian experience and a call for action. British Journal of Sports Medicine. https://doi.org/10. 1136/bjsports-2020-102306.

Deutsch, M., \& Gerard, H.B. (1955). A study of normative and informational social influences upon individual judgment. Journal of Abnormal and Social Psychology, 51(3), 629-636. https:// doi.org/10.1037/h0046408.

Depoux, A., Martin, S., Karafillakis, E., Preet, R., WilderSmith, A., \& Larson, H. (2020). The pandemic of social media panic travels faster than the COVID19 outbreak. Journal of Travel Medicine. https:// doi.org/10.1093/jtm/taaa031.

Engebretsen, L., Bahr, R., Cook, J.L., et al. (2014). The IOC centres of excellence bring prevention to sports medicine. British Journal of Sports Medicine, 48, 1270-1275. https://doi.org/10. 1136/bjsports-2014-093992

Kalkhoven, J. T., Watsford, M. L., \& Impellizzeri, F.M. (2020). A conceptual model and detailed framework for stress-related, strain-related, and overuse athletic injury. Journal of Science Medicine and Sport. https://doi.org/10.1016/j. jsams.2020.02.002.
Kim, B. (2020). Effects of social grooming on incivility in COVID-19. Cyberpsychology, Behavior, and Social Networking. https://doi.org/10.1089/ cyber.2020.0201.

Leng, H. K. (2013). Methodological issues in using data from social networking sites. Cyberpsychology Behavior and Social Networking, 16(9), 686-689. https://doi.org/10.1089/cyber.2012.0355.

Lines, G. (2002). Villains, fools or heroes? Sports stars as role models for young people. Leisure Studies, 20(4), 285-303. https://doi.org/10. 1080/02614360110094661.

Mann, R., Clift, B., Boykoff, J., \& Bekker, S. (2020). Athletes as community; athletes in community: covid-19, sporting mega-events and athlete health protection. British Journal of Sports Medicine, 54(18), 1071-1072. https://doi.org/10. 1136/bjsports-2020-102433.

McCloskey, B., Endericks, T., Catchpole, M., Zambon, M., MacLauchlin, J., Shetty, N., et al. (2014). London 2012 Olympic and Paralympic Games: public health surveillance and epidemiology. The Lancet, 383(9934), 2083-2089. https://doi. org/10.1016/S0140-6736(13)62342-9.

McCloskey, B., Zumla, A., Ippolito, G., Blumberg, L., Arbon, P., Cicero, A., Endericks, T., Lim, P. L., \& Borodina, M. (2020). Mass gathering events and reducing further global spread of COVID19: a political and public health dilemma. The Lancet. https://doi.org/10.1016/S01406736(20)30681-4.

Memish, Z. A., Steffen, R., White, P., Dar, O., Azhar, E.I., Sharma, A., \& Zumla, A. (2019). Mass gatherings medicine: public health issues arising from mass gathering religious and sporting events. The Lancet, 393(10185), 2073-2084. https://doi.org/ 10.1016/S0140-6736(19)30501-X

Phua, J., \& Ahn, S. J. (2016). Explicating the 'like'on Facebook brand pages: the effect of intensity of Facebook use, number of overall 'likes', and number of friends' 'likes' on consumers' brand outcomes. Journal of Marketing Communications, 22(5), 544-559. https://doi.org/10.1080/ 13527266.2014.941000.

Raskin, A. (2020). Jazz star Donovan Mitchell 'contracts coronavirus after infected teammate Rudy Gobert was careless in the locker room, touching other players and their belongings' days before playfully tapping reporters' recorders. https://www.dailymail.co.uk/news/ article-8105267/Jazz-star-Donovan-Mitchellcontracts-coronavirus-infected-teammateRudy-Gobert-careless.html. Accessed on 14 September 2020.

Segrin, C., \& Rynes, K. N. (2009). The mediating role of positive relations with others in associations between depressive symptoms, social skills, and perceived stress. Journal of Research in Personality, 43(6), 962-971. https://doi.org/10. 1016/j.jrp.2009.05.012.

Schinke, R., Papaioannou, A., Henriksen, K., Si, G., Zhang, L., \& Haberl, H. (2020). Sport psychology services to high performance athletes during COVID-19. International Journal of Sport and Exercise Psychology, 18(3), 269-272. https://doi org/10.1080/1612197X.2020.1754616.

Smith, L. R., \& Sanderson, J. (2015). I'm going to Instagram it! An analysis of athlete self-presentation on Instagram. Journal of Broadcasting \& Electronic Media, 59(2), 342-358. https://doi. org/10.1080/08838151.2015.1029125.

Teigen, K.H., Normann, H.T.E., Bjorkheim, J.O., \& Helland, S. (2020). Who would you most like to like? Adolescents' ideals at the beginning and the end of the century. Scandinavian Journal of Education Research, 44(1), 5-26. https://doi.org/ 10.1080/713696661.

Wang, T., Du, Z., \& Zhu, F. (2020). Comorbidities and multi-organ injuries in the treatment of COVID19. The Lancet, 6736, 52-54. https://doi.org/10. 1016/50140-6736(20)30558-4.

Weinberg, A., \& Cooper, C. (2012). The nature of stress during turbulent times. In Stress in turbulent times. London: Palgrave MacMillan.

World Health Organization (2020). Coronavirus disease 2019 (COVID-19). Situation report. https://www. who.int/docs/default-source/coronaviruse/ situation-reports/20200303-sitrep-43-covid19.pdf? sfvrsn $=2 c 21 c 09 c \_2 . \quad$ Accessed 13 September 2020

Zheng, Y. Y., Ma, Y. T., Zhang, J. Y., et al. (2020). COVID-19 and the cardiovascular system. Nature Reviews Cardiology. https://doi.org/10.1038/s41569020-0360-5. 